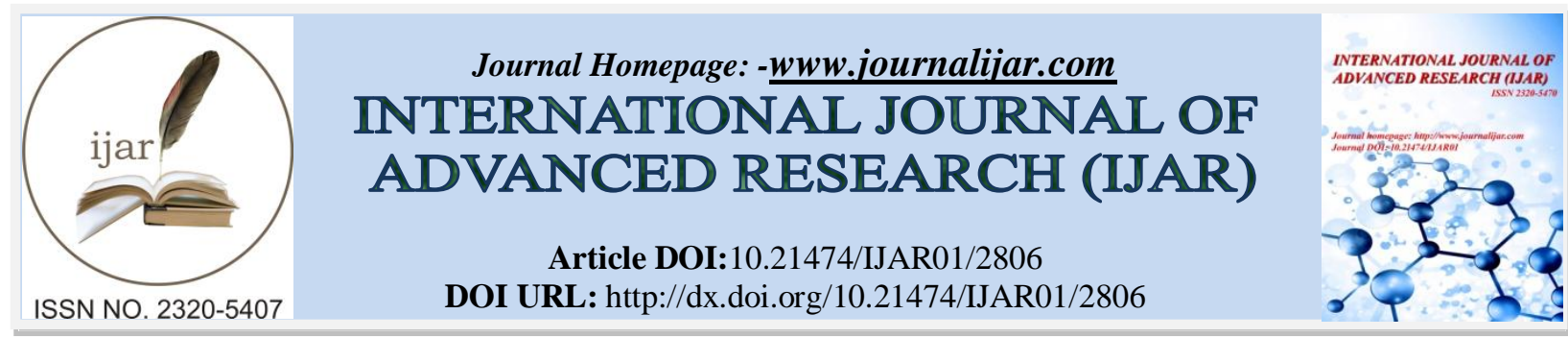

RESEARCH ARTICLE

\title{
ANGIOLEIOMYOMA OF THE NASAL CAVITY \\ An Unusual Tumor.
}

\begin{abstract}
Mustafa Jamal Al Khanani ${ }^{1}$, Abdullah Alrasheedi ${ }^{1}$, Jameel Nasser Alswaheb ${ }^{1}$ and Haitham Nasser ${ }^{2}$.
1. Department of ORLHead and Neck surgery, King Saud Medical City, Riyadh, KSA.

2. Department of Histopathology, King Saud Medical City, Riyadh, KSA.
\end{abstract}

\section{Manuscript}

Manuscript History

Received: 15 November 2016

Final Accepted: 17 December 2016

Published: January 2017

Key words:-

Nasal Cavity, Angioleiomyoma.

\section{Abstract}

ABSTRACT: Angioleiomyoma is a benign tumor arising from the vascular smooth muscle (tunica media) and presents commonly between third and fifth decades of life. Although there are sporadic reports about this tumor in the literature, none describes all the information in detail. It is an extremely rare benign tumor. Since the first case reported by Maesaka et al in 1966, only 30 cases of angioleiomyoma of the nasal cavity have been published in English literature. Angioleiomyoma presents as a painful mass in approximately $60 \%$ of the cases. Pre- operative diagnosis is difficult, but with a high index of suspicion and awareness, it is possible. The use of ultrasound and magnetic resonance imaging should be considered. It causes minimal morbidity and excision is usually curative. Histological examination using smooth muscle Actin stain portraits the smooth muscle bundles clearly. We report here a case of angioleiomyoma of nasal cavity in a 33 years old female presented with a mass in Rt. Nasal cavity, manifested mainly with nasal obstruction.

Copy Right, IJAR, 2016,. All rights reserved.

\section{Introduction:-}

OBJECTIVE: To describe rare benign nasal lesion like Angioleiomyoma that present as a nasal mass and can be cured by simple surgical excision. Angioleiomyoma is uncommon benign tumor of the nasal cavity and are relatively rare. Reporting and assisting the systematization of more accurate diagnostic methods in clinical and complementary investigation of vascular leiomyoma in the nasal cavity. It is extremely rare tumor of nasal cavity that represents less than $1 \%$ of all vascular leiomyomas. It is more prevalent in women between the fourth and sixth decades, reaching primarily the inferior nasal turbinates.

It is composed of smooth muscle cells with a variable amount of fibrous stroma in the vascular wall or by remnants of embryonic tissue, commonly found in the uterus (95\%), skin (3\%) and gastrointestinal tract $(1.5 \%)^{1,2}$

Less than $1 \%$ of all vascular leiomyomas occur in the nasal cavity ${ }^{3,4}$ Hachisuga et al describe only 48 cases $(8 \%)$ of angioleiomyoma in the head \& neck in a study with 562 cases. Only 5 of the 48 cases were located in the nasal cavity, accounting for $1 \%$ of all angioleiomyomas. ${ }^{5}$

Leiomyoma has many variants. They are classified in three groups: leiomyoma, angioleiomyoma and epithelioid leiomyoma. ${ }^{6}$ Angioleiomyoma or vascular leiomyoma accounts for approximately $4 \%$ of benign soft tissue tumors. 
Most angioleiomyomas occur in the extremities, especially the lower extremity, and other sites include the head \& the trunk. ${ }^{7}$ The tumors are usually located in the subcutis and less often in the deep dermis.

Maesaka et al reported the first case of angioleiomyomanin the nasal cavity in $1966 .{ }^{8}$ Only 30 cases have been documented in English literature. Forty nine additional cases have been reported in the Japanese literature. ${ }^{9}$

The origin of angioleiomyoma of the nasal cavity is uncertain, partly due to the scarcity of smooth muscle in the nasal cavity. Three hypotheses have been proposed for the origin of smooth muscle tumors in the nasal cavity: from aberrant undifferentiated mesenchymal cells; from elements of smooth muscle in the walls of blood vessels and of piloerector muscles; or from both previous hypotheses, simultaneously. ${ }^{2,10-13}$ Some articles indicate that sexual hormones and Epstein- Barr virus infection can affect the genesis of nasal angioleiomyoma. 3,14

The literature shows a prevalence of angioleiomyomas of the nasal cavity in female patients (in a 2:1 ratio between females and males) between the fourth and sixth decades of life, and affecting mainly the inferior nasal conchae. ${ }^{9,11}$ These angioleiomyomas develop in the mucosa of the nasal cavity as single solid small cutaneous masses. They can be painful or not and can expand. ${ }^{4,14}$ They usually manifest as epistaxis and with nasal obstruction. ${ }^{11}$

Computed tomography (CT) and magnetic resonance do not conclude the diagnosis. Cytologic examination does not provide a conclusive diagnosis. Surgical excision with histologic examination is the only way to make a definite diagnosis. ${ }^{4}$ In addition to that, conventional light microscopy studies for the identification of angioleiomyoma after staining with hematoxylin- eosin can be performed using special staining, such as Masson trichrome stain, or immunohistochemical markers such as smooth muscle actin, desmin, myoglobin, S-100 protein, and vimentin. The absence of atypias is the most important histologic indication of benignity. The treatment of choice is total excision of the lesion. ${ }^{2,10,12-15}$ Recurrence is extremely rare after total excision.

\section{Case report:-}

A 33 years old female admitted in the ENT Department of KingSaud Medical City with complaints of nasal obstruction and episodes of small volume epistaxis. The patient's medical and family histories were unremarkable. Physical examination and nasal endoscopy, showed the presence of a reddish mass which occupied the whole rt. nasal cavity and preventing the progression of the nasofibroscope. CT scan showed a lobulated enhancing soft

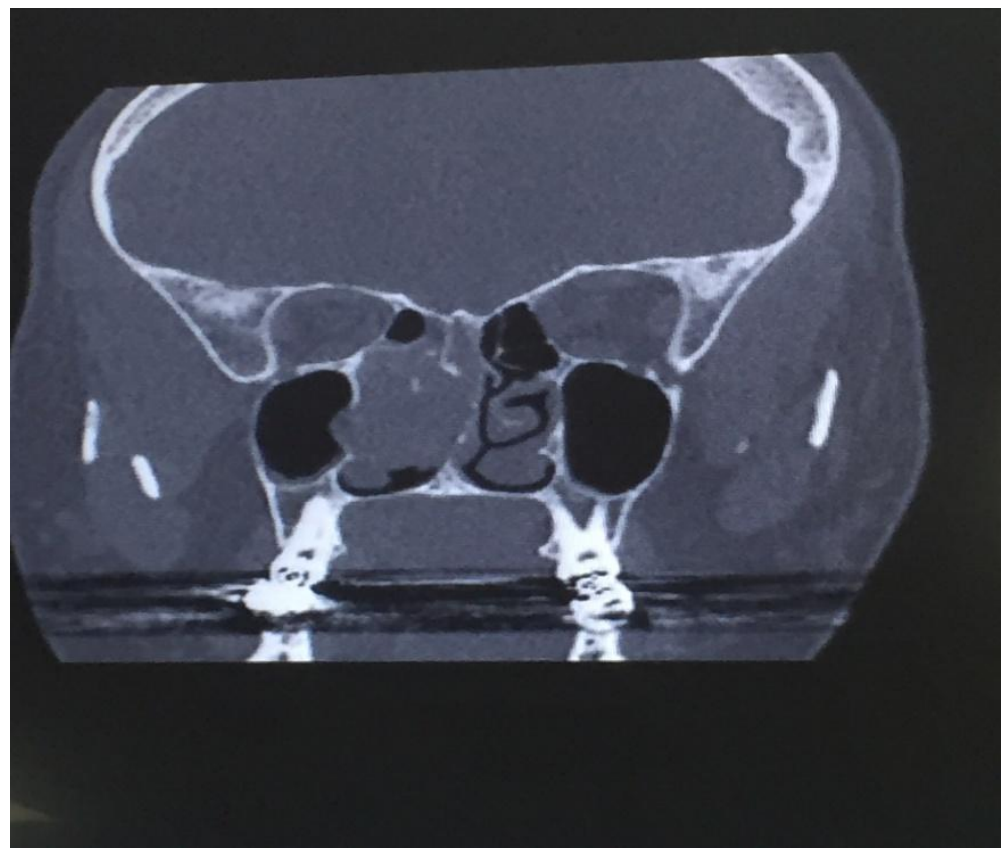

Fig:1 CT scan showing mass involving Rt. nasal cavity 
tissue mass in Rt. nasal cavity extending upward to involve the posterior ethmoid sinus (Fig 1). No intracranial extension of the lesion seen and no bony defect seen in the skull base. The patient underwent surgical excision of the mass. Grossly, the excised specimen measured $3 \times 3 \times 1 \mathrm{~cm}$ and was soft. On microscopic examination the tumor (Fig: 2 A, B, C) demonstrated a proliferation of thick walled blood vessels admixed with a monomorphic spindle cell population without necrosis, vessels \& admixedspindle cells ( intermediate magnification)pleomorphism or increase in mitosis. This spindle cell proliferation stained positive for Vimentin and h-Caldesmon and smooth muscle actin (SMA) immunostain. Postoperatively, the surgical wound healed well with normal scarring.

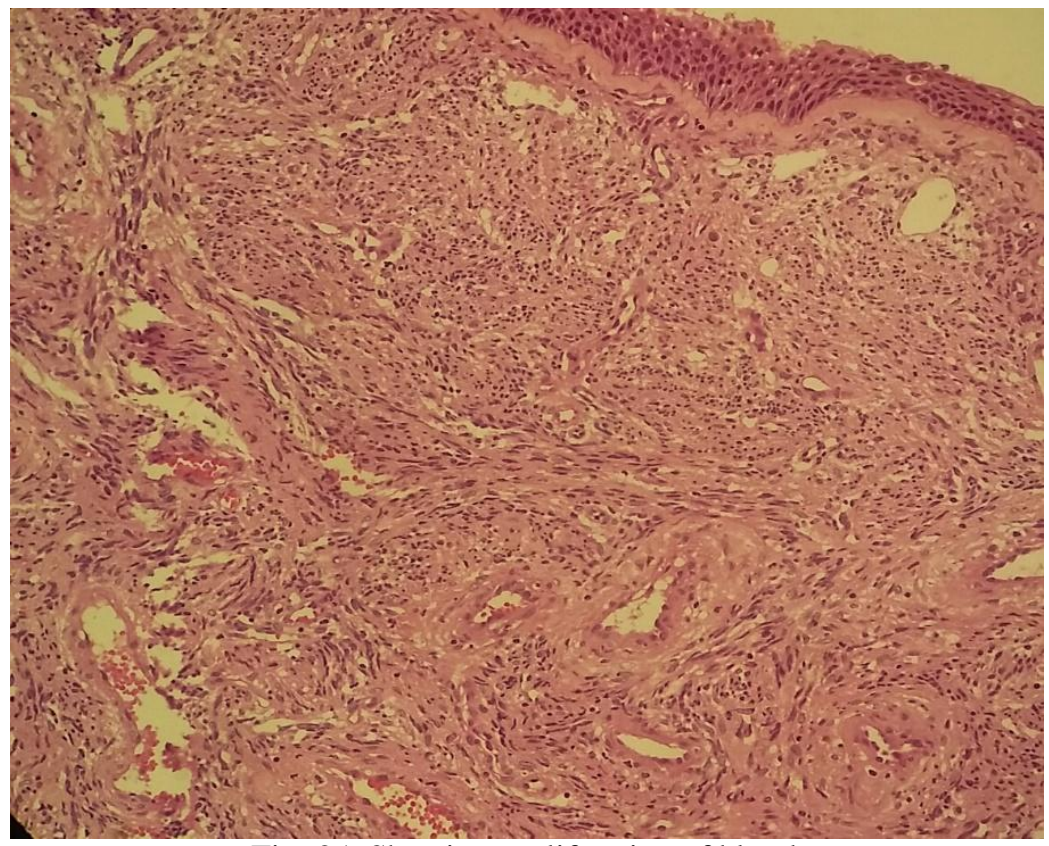

Fig: 2A Showing proliferation of blood

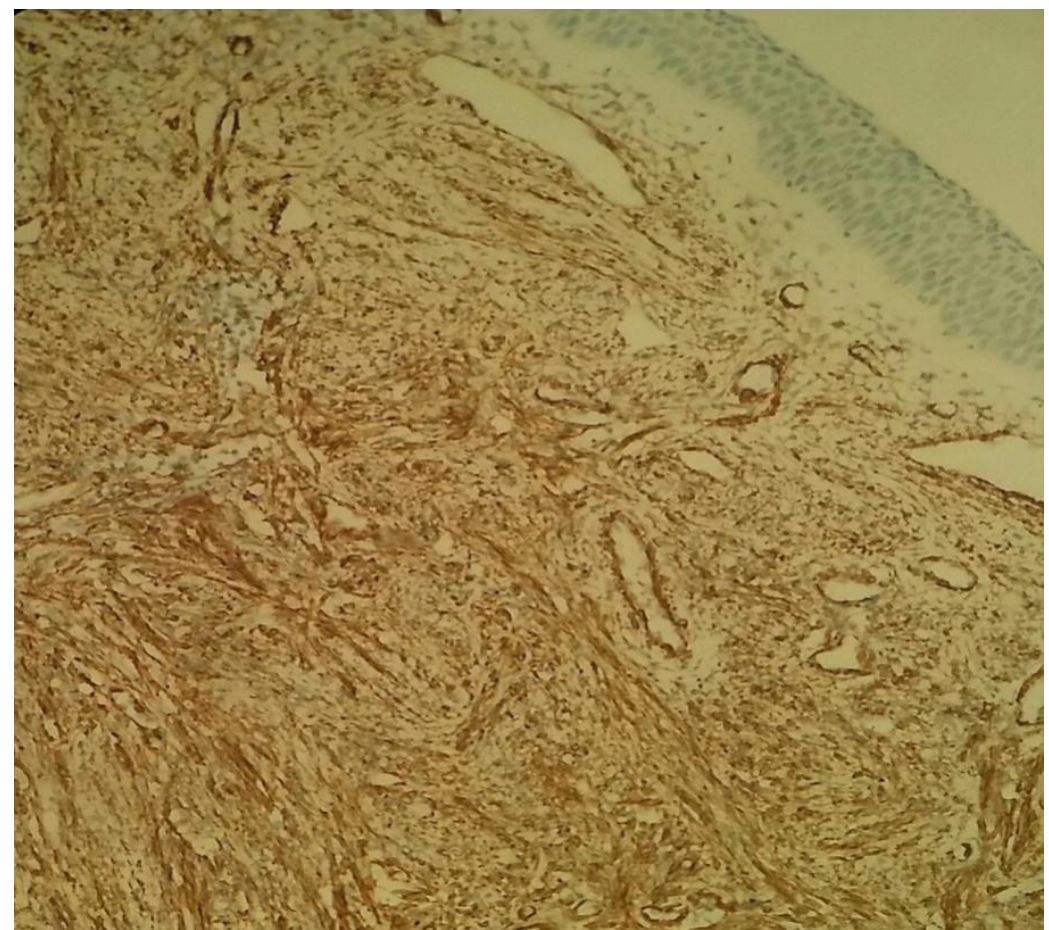

Fig: 2B Showing staining patterns with h-Caldesmonimmunostain(intermediate magnification) 


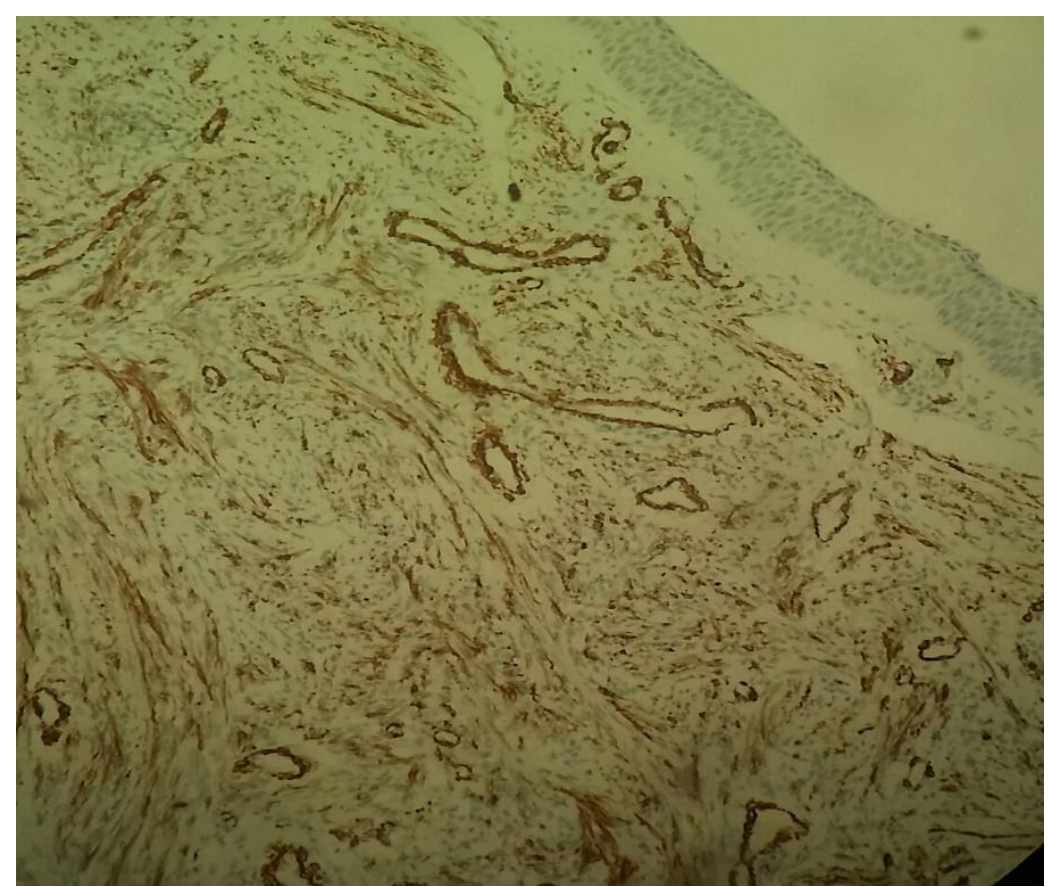

Fig: 2C Showing focal staining pattern with SMA immunostain (intermediate magnification)

\section{Discussion:-}

Angileiomyoma is a rare, benign, smooth muscle tumor arising from the tunica media of veins and is seldom diagnosed before surgery. Angioleiomyoma can be found throughout the body but occurs most frequently in the lower extremities. ${ }^{5,16-20}$ It commonly arises in the dermis or subcutaneous tissue. ${ }^{17}$ A majority of these tumors are quite small, generally less than $2 \mathrm{~cm}$ in diameter. ${ }^{16-19}$ Nasal cavity angioleiomyomas are extremely rare. The paucity of smooth muscle in the nasal cavity might explain why the tumors were rare. It is rarely included in the differential histopathologic diagnosis. ${ }^{4}$ Other tumors of the nasal cavity are: nasal angiofibroma, inverted papilloma, malignant lymphoma, fibromyoma, leiomyoblastoma, hemangiopericytoma, angiosarcoma, angiomyolipoma, and vascular leiomyosarcoma. ${ }^{12}$ The most affected nasal sites are the nasal septum, the inferior turbinate and the vestibule. The other sites are superior and middle turbinate. The most common symptoms are nasal obstruction associated frequently with epistaxis. The other symptoms are headache and facial pain.

Radiologically, the images are not specific, ${ }^{11}$ but CT and MRI could provide the information about the extent of the lesion. It usually presents, macroscopically, as a solitary, well circumscribed or lobulated mass ranging from 5 to $20 \mathrm{~mm}$. Microscopically, angioleiomyoma is separated into three subtypes: solid, venous and cavernous. It is characteristically composed of smooth muscle cells which are mature and well differentiated and numerous walled vessels. Mitotic figures are usually abscent or very rare.

Most angioleiomyoma was diagnosed by microscopy with conventional Hematoxylin and Eosin staining. Differential diagnosis arise rarely with other spindle cell tumors such as angiofibroma, fibroma angiomyolipoma and angiosarcoma. Immunohistochemical examination can be helpful in these cases.

The etiology of sinonasal angioleiomyoma remains uncertain. Nasal cavity contains smooth muscle tissue in the walls of blood vessels and in the hair erecting muscles of the anterior vestibule. ${ }^{11}$, The advanced theories of this neoplasm are that the tumor cells derive from the wall of vessels, from the hair erecting muscles or from some aberrant undifferentiated mesemchyma. Some authors documented case of a nasal leiomyoma and angioleiomyoma which express progesterone receptor. ${ }^{2,22}$ They suggest that the growth of this tumor may be hormone dependent.

The treatment of choice is local surgical excision. ${ }^{2}$ No recurrences were reported in follow up studies of nasal cavity angioleiomyoma. 


\section{Conclusion:-}

Angioleiomyoma of the nasal cavity is a rare benign tumor that is difficult to diagnose clinically and requires a detailed and invasive investigations. The complementary tests should guide the diagnostic reasoning; however, we concluded that it is essential to perform postoperative histopathological study to make a definite diagnosis of angiolriomyoma of the nasal cavity.

\section{References:-}

1. EnzingerFM,Lattes R, TorloniInternacional H. Classificacaohistologica de tumors: tipagemHistologica dos tumors de tecidos moles.2a ed.Geneva, Switzerland: Organizacao Mundial deSaude- Springer Verlag; 1969

2. Marioni G, MarcheseRagona R, Fernandez S, Bruzon J, Staffieri M, Staffieri A. Progesterone receptor expression in angioleiomyoma of the nasal cavity. Acta Otolaryngol. 2002 Jun; 122(4): 408-412.

3. Wang CP, Chang YL, Sheen TS. Vascular leiomyoma da cabeca e pescoco. Laryngoscope 2004; 114:661-665.

4. Chen CJ, Lai MT, Chen CY, Fang CL. Vascular leiomyoma of the nasal cavity: case report. Chin Med J (Engl) 2007; 120(4):350-352.

5. Hachisuga T, Hashimoto H, Enjoji M. Angioleiomyoma: a clinicopathologic reappraisal of 562 cases. Cancer 1984; 54:126-130. [PubMed] Michaeal RC, Shah S. Angioleiomyoma of the nasal cavity. Indian J PatholMicrobiol. 2009 Jul- Sep; 52 (3):386-8.

6. Fletcher C.D.M., Unni K.K., Mertens F. (Eds.): World Health Organization Classification of Tumors. Pathology and Genetics of Tumors of Soft Tissue and Bone. IARC Press: Lyon 2002.

7. Maesaka A, Keyaki Y, Nakahashi T. Nasal angioleiomyoma and leiomyosarcoma-report of 2 cases. Otologia (Fukuoka) 1966; 12:42-47.

8. Singh R. Hazarika P, Balakrishnan R, Gangwar N, Pujary P. Leiomyoma of the nasal septum. Indian J Cancer 2008; 45(4):173-175.

9. Michael RC, Shah S. Angioleiomyoma of the nasal cavity. Indian J MicrobiolPathol 2009; 52(3):386-388.

10. Campelo VES, Neves M, Nakanishi MC, Voegels RL. Angioleiomyoma de Cavidade nasal: relato de um caso e revisai de literature. Braz J Otorhinolaryngol 2008; 74(1):147-150.

11. Shankar PR, Subish P. Disease mongering. Singapore Med J 2007; 48(4):275-280.

12. Ikeda K, Kuroda M, Sakaida N, Maehara M, Ohmura N, Sawada S. Cellular leiomyoma of the nasal cavity: findings of CT and MR imaging. AJNR Am J Neuroradiol 2005; 26:1336-1338.

13. Fonseca MT, Araujo PAK, Barreiros AC. Leiomyoma de seio paranasal: Relato de um caso e revisao da literature. Braz J Otorhinolaryngol 2002; 68(3)43439.

14. Cintra C. PPV, Lima WTA, AR Junior. Leiomyoma da Cavidade nasal: relato de caso. Braz J Otorhinolaryngol 2007; 73(6); 851.

15. Duhig JT, Ayer JP. Vascular leiomyoma: a study of 61 cases. Arch Pathol. 1959; 68:424-430. [PubMed]

16. Morimoto N. Angioleiomyoma (vascular leiomyoma): a clinicopathologic study. Med J Kagoshima Univ.1973; 24:663-683.

17. Freedman AM, Meland NB. Angioleiomyomas of the extremities: report of a case and review of the Mayo Clinic experience. PlastReconnstr Surg. 1989; 83:328-331. [PubMed]

18. Domanski HA. Cytologic features of angioleiomyoma: cytologic- histologic study of 10 cases. DiagnCytopathol. 2002; 27:161-166. [PubMed]

19. Hasegawa T, Seki K, Yang P, et al. Mechanism of pain and cytoskeletal properties in angioleiomyomas: an immunohistochemical study. Pathol Int. 1994; 44:66-72. [PubMed]

20. He J, Zhao LN, Jiang ZN, Zhang SZ. Angioleiomyoma of the nasal cavity: a rare cause of epistaxis. Otolaryngol Head neck Surg. 2009Nov; 141(5); 663-4.

21. Tseng PY, Lai YS, Chen MK, Shen KH. Progesterone receptor expression in sinonasal leiomyoma: a case report and review of the literature. Int J ClinExpPathol2014; 7(3):1224-1228. 